\title{
Leveraging Social Media Cloud and Hadoop Frame Work to Help the Disasters Rescue Team
}

\author{
Raguvaran.S ${ }^{1}$, Joyce Beryl Princess.P ${ }^{2}$ \\ KPR Institute of Engineering and Technology, Coimbatore, Tamil Nadu, India
}

\begin{abstract}
Anthropogenic and natural hazards adversely affect human, eco system and infrastructure of our nation. In 2015, both Chennai flood and Nepal earthquake caused significant damage to the mankind and country. Since the information about the post disaster scenario is inadequate, NDRF (National Disaster Response Force) struggles a lot to rescue the victims from the affected area. Collecting, sharing, and delivering information in disaster situations is crucially important. We are likely to create big data and social media cloud based framework to collect, analyze and deliver the required information to help the government to save the life's after Disaster. Firstly, this system crawls into the social media cloud, especially Twitter, Facebook to mine disaster-related tweets and Statuses in real time. This system incorporates data analytics phase to provide the accurate and precise information about the post disaster scenario in real time. Secondly, the locations from where the Tweets and Status which has been updated is monitored and the locations are stored in a cloud database. Further the database is shared with the NDRF which will help the rescue process to be done quickly.
\end{abstract}

Keywords: NDRF, Big data, Facebook, Twitter

\section{INTRODUCTION}

The number of disaster occurring is periodically increasing. This in turn affects the economy of the country. Major disasters like tsunami, earthquakes and flood affect the regular life and the resettlement after the occurrence of the disaster is a major task to be carried out.

The April 2015 earthquake in Nepal caused more than death of 7000 people and injured more than 10,000 ,destroying buildings and monuments. Its impact was also felt on adjoining areas of India, China Bangladesh and Bhutan. Kathmandu twisted into a disaster zone. In India the 2013 flood in Uttarakhand caused the death of 5700 people. According to Munich RE statistics, disasters. In this paper we

Demonstrate how contents like the average no of disasters have been increased to 730 in the last decades as compared to 1980's and 1990's. Even though the world has its own advanced automation, major natural calamities like earthquakes, flood takes a levy upon the human world. The disasters relief and resettlement requires correct planning to make it faster. Information and communication technology in disaster management is upcoming so large amount of data is generated. Social media supports backchannel communication allows for wide scale interaction. The amount of data gathered rises promptly day by day. On the other side, there are more traffic flow in communication through social network.

Today disaster affected areas faces the following threats.

- Administrators' dreath a clear strategy for sending the rescue teams over the damaged area which delays the emergency response.

- It becomes tedious job for rescue troops arriving from outside the disaster-affected zone.

- Lack of proper communication leads to crash of electronic communication

\section{YSTEM ARCHITECTURE}

The system architecture involves both primary data sources and secondary data sources. 


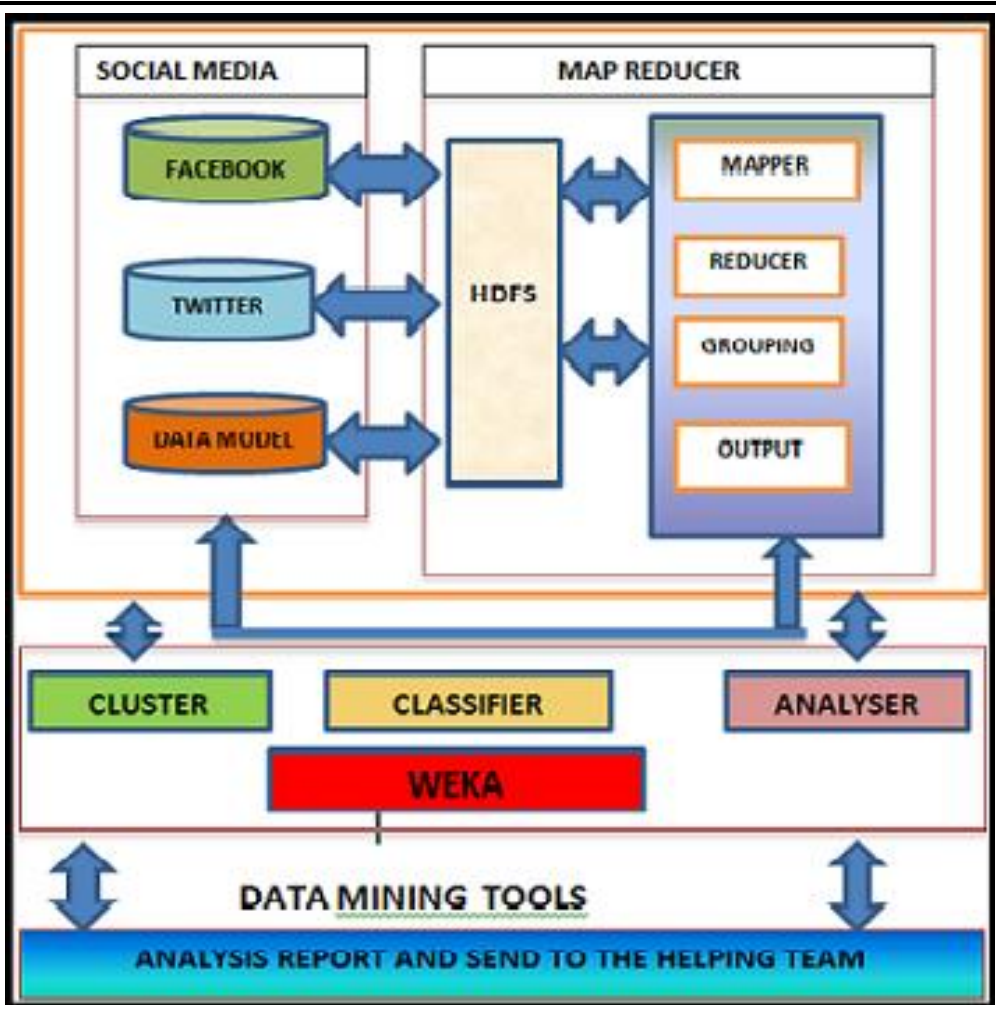

\section{DATA FROM SENSORS}

\section{Vibration Sensor}

It can be highly useful during earthquakes, cyclone and flood. We can receive information from these vibrational sensors after the disaster and these data are useful for the evacuation of affected people from disaster affected areas.

\section{Wireless Body Sensor}

In critical medical emergency situation, wireless body area network rigged health monitoring systems treat data packets with critical information regarding patient's health in the same way as data packets bearing regular healthcare information. In this patients could wear the body sensor for both emergency and regular health care monitoring so the experts could analyze the status of the victims.

\section{Cloud and Servers}

Cloud is the delivery of demand computing resources everything from applications to data centers over the internet on a pay for use basis. It also refers to a distinct IT environment. It is also used for remotely provisioning scalable and measured IT resources.

\section{Social Network Cloud}

We can collect information from various social Medias like Facebook and twitter and combine it to provide details about the emergency's harshness of disaster prone areas. The chatters, status and tweets, interviewed directly from the victims are feed to the clouds so that the affected zones can be properly identified. So that we can help the rescue troop for clear planning of the resettlement.

\section{Health Care Cloud}

This cloud is used to gather the data from the different body sensors to recognize the health condition and the physiological status of the victims and to monitor and analyze the health condition of the affected areas.

\section{Social Media Cloud}

In social media cloud the data are being collected and feed to clouds from the article of rescue teams published in the newspapers, interviews in the media and surveys collected from the victims and disaster prone region. So that it helps in analysis and the planning of the rescue management after the occurrence of disasters, so that resettlement in the affected zone is easier for the rescue team. 


\section{Clouds in Collusion}

We are introducing various clouds to for the purpose of emergency evacuation and resettlement of the disaster affected areas. There may be various difficulties in communicating between affected areas and the rescue teams and the details may inadequate and inaccurate for the analysis at the time of the disasters. To solve those problems we are combining the heterogeneous data collected from various sensors and cloud. In our system we are unifying the data collected from various secondary sources like cloud it helps in performing the real-time analysis of the damages and severity of the disaster. And we also use the advanced big data technologies along with the cloud platform.

\section{Management of Obtained Data}

The numerous amounts of data collected from various sources should be organized for the proper analysis and planning for the rescue and emergency management. The data can be segregated based on their sources.

\section{Communication System}

First we consider the communication in the disaster affected zones which will be very difficult for us to trace out. Due to the occurrence of disaster there may be some network failures and there are some possibilities for the network congestion. To avoid the improper planning of the rescue team they should identify the distribution of the victims and there can be some vehicles equipped with communication system to avoid communication troubles and to identify proper route of the affected areas and to provide a communication channel between the officials and the victims. So that we can reduce the communication failures.

\section{MAP REDUCING}

\section{Big Data Analtics}

After the data set collection from sources like sensors and loud the major work is to manage this huge voluminous data. For example, March 2011 Japan had the major earthquake and subsequent tsunami with 8.9 magnitude. There were numerous tweets across the world .It's around 5,530 tweets per second. In such a situation we are using a infrastructure capable of managing high velocity and numerous data, in other words big data system is used to gather the data and we are coordinating the rescue teams according to the severity of the disasters. And we are also considering the analog communications from which we can track the location of the people using the GPS. The sensors also provide the data of the environmental condition of the affected area. And the body sensors used can provide us with the health condition of the living victims. From these various sources we can clearly map the movement of people in affected zone and the rescuing would become even easier. We can also identify the disaster spread patterns from the sensors. Based on all these information and various kinds of data the rescuing team can plan for clear and easy way of resettlement of the affected victims from the affected area.

Map Reducing is a programming model and an associated implementation for processing and generating large data sets with the parallel, distributed algorithm on a cluster.

\section{Algorithm}

Word count mapper using the "in-mapper combining"

\section{1: class Mapper}

2: method Initialize

3: $H \leftarrow$ new AssociativeArray

4: method Map(docid a, doc d)

5: for all term $t \in$ doc $d$ do

6: $H\{t\} \leftarrow H\{t\}+1 . \quad$ Tally counts across documents

7: method Close

8: for all term $t \in H$ do

9: Emit(term $t$, count $H\{t\})$ 


\section{Resettelment and Assesment Policies}

Here we are using Hadoop platform where the Weka tool and Rapid miner tool are used The data that are in social media clusters are collected and stored by mongoDB. The HDFS (Hadoop Distributed file systems) extract the required data and provide it to Map Reducer where the data are mapped, reduced and grouped to give the required output. The output details clustered and classified then, using the weka tool the analysis report for the disaster management is given to the rescue team. So that they could get a clear view about the affected zone, victims conditions so that they make a clear planning for the rescuing and resettling people. This is mainly for the post disaster scenario where victims are provided with good environmental condition without getting affected from any diseases and giving them better psychological

\section{RESUlt}

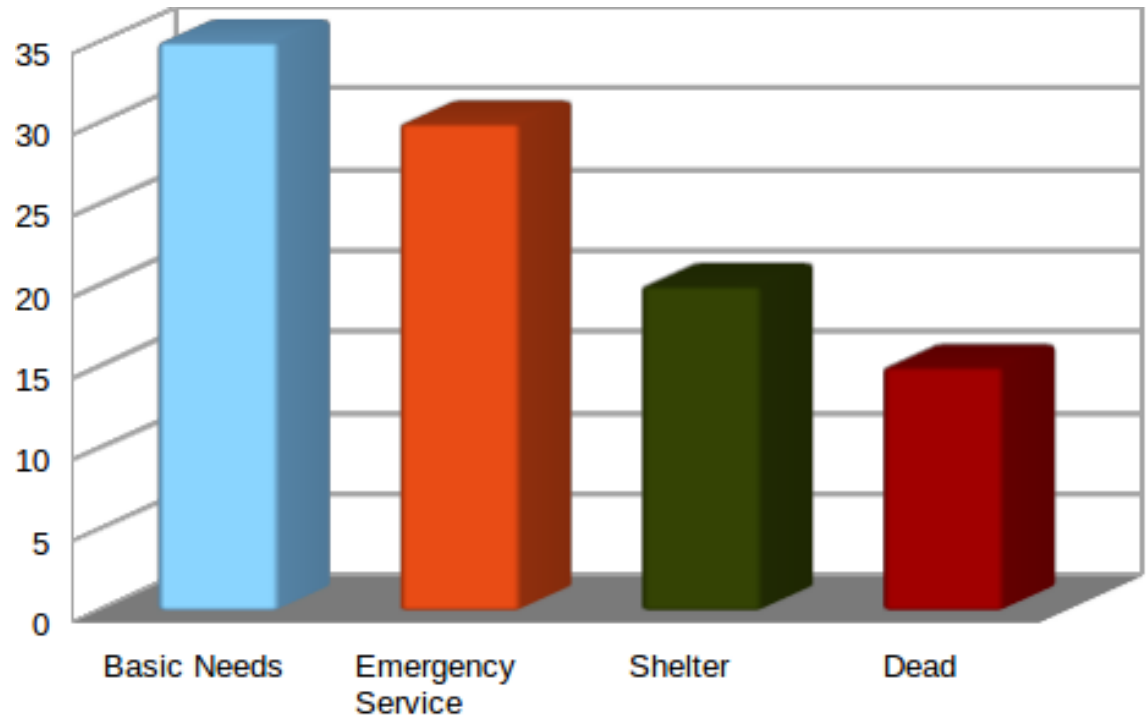

\section{CONClusion}

This study concludes that there are many reasons in using social media by people all over the world. Nowadays the most favored among all is creating networking, while the others were the least. The social media is the most trusted form of communications. Overall the social media is most visible and plays an important role. It is the cheapest, efficient and convenient marketing and communication tool. So it is very useful for resettling the disaster affected zones. Thus it gives a clear planning for safeguarding people and can be employed to reduce the expenditure caused due to improper planning.

\section{REFERENCES}

[1] "Wireless Body Sensor Networks: Technologies, Applications, Markets and Prospects," PRNewswire, 26 Sept. 2014; www.prnewswire.com/news-releases/wireless-body-sensornetworks-technologies-applications-markets-and-prospects-277194451.html.

[2] G. Sheftick, "Body Sensors to Help Soldiers in Future Conflicts," Army News Service, 12 Sept. 2014; www.army.mil/article/133577/Body -sensorsto-help-Soldiers-in-future-conflicts

[3] “The Top 15 Tweets-Per-Second Records, "Mashable, http://mashable.com/2012/02/06/tweets per-second-records-twitter.

[4] Evacuvation and Emergengy Management using federated cloud, Subhadeep Sarkar, Subarna Chatterjee, and Sudip Misra, Indian Institute of Technology, Kharagpur.

[5] David Sims., "A CRM Insider's Views on Social Media, Face book and Web 2.0", Customer Interaction Solutions. Vol. 27, no.5; pp.2, 2008 